\title{
Nassirya: una serie italiana entre ficción y realidad histórica ${ }^{1}$
}

\author{
Anna Maria LoRUSSO* \\ annamaria.lorusso@unibo.it \\ Patrizia VIOLI** \\ patrizia.violi@unibo.it
}

Traducido por: Melina Márquez García-Largo

(Abstracts y palabras clave al final del artículo)
Enviado: 20 de abril de 2013
Evaluado: 21 de junio de 2013
Aceptado: 12 de julio de 2013

La memoria cultural tiene su núcleo antropológico en la conmemoración de los difuntos Assmann (2002: 35)

El 12 y 13 de marzo de 2006, en el Canal 5, se estrena en horario de máxima audiencia una miniserie de dos episodios con el título: Nassirya: para no olvidar, una invitación explícita a recordar la muerte del contingente italiano ocurrida en Irak tres años antes, el 12 de noviembre de $2003^{2}$.

La miniserie se manifiesta como un claro ejemplo de la ficción italiana contemporánea por al menos tres tipos de factores, de los cuales los dos primeros son de naturaleza estructural: la singular organización temporal de la serialidad y la referencia a hechos reales.

Sobre el tercero, de carácter temático, centraremos nuestro análisis: la constante elaboración y valoración de lo que podríamos definir como el valor de la "italianidad". Con respecto a las dos características que hemos definido como estructurales, ya en su informe anual sobre la ficción del 2003, Milly Buonanno señalaba como específico de nuestra ficción precisamente estos factores, que en el caso de Nassirya se presentan interconectados con el tercero: "el formato predilecto de la ficción italiana es y sigue siendo la miniserie, en la línea de una tradición que se remonta a las series culturales anteriores a los ochenta" (Buonanno 2003:20); "lo que distingue a la actual ficción italiana es la necesidad de recuperar, valorar y reconstruir el patri-

\footnotetext{
* Anna Maria Lorusso es profesora de Semiótica en la Universidad de Bolonia, Italia.

** Patrizia Violi es catedrática de Semiótica en la Universidad de Bolonia, Italia.

${ }^{1}$ Este artículo fue publicado en: M. P. Pozzatto y G. Grignaffini (eds) Mondi seriali. Percorsi semiotici nella fiction. Bologna, RTI, 2008.

${ }^{2}$ Precisamente, el atentado ha causado diecinueve víctimas: doce carabinieri, cinco soldados y dos civiles.
} 
monio de la memoria colectiva de personajes, eventos, momentos, experiencias vividas o transmitidas por la historia política, religiosa o cultural del país" (ivi: 22).

Si la breve duración de la miniserie se remonta a los gloriosos años de las primeras series, en nuestro caso cabría preguntarse si una ficción en sólo dos episodios, emitidos durante dos tardes consecutivas, es aún una serie o más bien, simplemente, una película televisiva en dos episodios a la que se le ha atribuido el carácter de serie de ficción por razones de marketing. Obviamente la asignación a un género o a otro depende de su definición; - pero no es nuestra intención adentrarnos aquí en este problema. Sin embargo, no se puede obviar cómo en nuestro caso faltan muchas de las características que normalmente se atribuyen a las series televisivas, y no solamente por la limitada extensión temporal. Es la estructura interna de los episodios la que es problemática en este caso, porque están ausentes todas las marcas que, aisladamente o en combinación las unas con las otras, caracterizan por norma las series televisivas: el (relativo) cierre de cada capítulo, la división de la trama para crear expectativas y mantener el indispensable suspense que "fidelice" al espectador. El cierre de la historia en el segundo episodio impide además cualquier posibilidad, aunque sólo fuera imaginaria, de continuar la serie en un futuro. Un tanto bruscamente, podríamos decir que Nassirya no es una serie por la banal razón de que sabemos que terminará pronto y también cómo terminará. Por otro lado, el final es ampliamente anunciado desde las primeras escenas del primer episodio, que anticipan la trágica conclusión. El cierre de la historia queda, de este modo, introducido textualmente desde el principio, o confiado a la enciclopedia de los telespectadores, ya que sería difícil suponer un escaso conocimiento del evento real narrado por la ficción.

Esto nos lleva a nuestra segunda consideración: en Nassirya está presente una relación específica entre la temporalidad de la serie y el vínculo ficción/realidad. La serie alargada en el tiempo lleva a una potencialidad ilimitada de ulteriores desarrollos narrativos, mientras que la realidad de un evento como el atentado en Nassirya implica un inevitable y definitivo cierre temporal.

Pero la relación ficción/realidad está abierta también a otras consideraciones. Es algo ampliamente reconocido que la oposición entre ficción (es decir, relato de fantasía, imaginario) y realidad, aparentemente en la base del género, es menos relevante de lo que parecería a primera vista, y resulta ampliamente rebatida por el carácter híbrido presente hoy en todos los géneros y que caracteriza la reality tv contemporánea. En particular, como decíamos al principio, la ficción italiana se ha caracterizado siempre por un fuerte vínculo entre personajes y hechos reales, que remiten a la historia y a la experiencia del país. Pensemos en todas las series basadas en personajes históricos o de la actualidad, desde María Montessori a Padre Pío, Falcone y Borsellino, por citar sólo algunos ejemplos. En todos estos casos la ficción establece, ya sea a nivel de su desarrollo narrativo, ya en la descripción de los personajes, vínculos de fidelidad con la realidad de los hechos. Naturalmente algunos de los detalles podrán ser modificados, pero no los nudos fundamentales de una vida o de un hecho. El carácter "cerrado" de las que podríamos llamar, con un oxímoron, "ficción de realidad" -que tanta importancia tienen en la producción italiana-, nace precisamente a raíz de estos vínculos. En el caso de Nassirya, estos vínculos se presentan como especial- 
mente delicados y necesarios, debido al carácter de tragedia nacional del evento al que hace referencia. ¿En qué medida puede ser "ficcionalizado" un evento tan trágico? ¿Cuánto pueden ser forzados los límites de realidad?

Se encuentran, o quizás se enfrentan, aquí dos lógicas narrativas y de valor diferentes, y en ciertos casos fuertemente antagonistas: la exigencia de respetar la realidad histórica de los hechos, y esa narrativa propia de la ficción, con sus necesidades de convertir en espectáculo, crear contrastes patéticos y temáticos, simplificar y tipificar a los personajes. Veremos con detalle más adelante cómo estas tensiones son puestas en juego y resueltas, sustancialmente siempre en función de esa valoración de la italianidad que constituye el verdadero hilo conductor de la serie. En Nassirya el anclaje al plano de la realidad, además de en el mismo título, está garantizado por las escenas que cierran el segundo y último episodio de la serie, y que retoman en primer lugar las escenas de los funerales públicos de los muertos de Nassirya, transmitidas en directo por la Rai; y después las fotos y los nombres de los "verdaderos" carabinieri asesinados. Todo ello, a través un montaje que recuerda explícitamente a análogos cierres cinematográficos, en los que aparecen las caras y los nombres de los actores que han dado vida a los diferentes personajes.

Justamente esa continua oscilación entre el plano de la realidad y el de la ficción constituye una de las características más específicas de nuestro texto: producido explícitamente "para no olvidar", como dice el subtítulo, lo que establece un vínculo complejo y no lineal con la memoria histórica que se propone perpetuar. Si por un lado, de hecho, Nassirya es una ficción "celebrativa", cuya función proclamada es la de mantener una memoria histórica de un evento dramático muy reciente, al mismo tiempo contribuye a la construcción de una nueva memoria, precisamente ficcional, del mismo hecho. Se crea en este proceso una especie de "hibridación" de la memoria, que termina contaminando elementos ficcionales y anclajes referenciales en la realidad. A pesar de la inscripción sobre el plano real de nombres y caras de militares asesinados, para el espectador televisivo el verdadero héroe de Nassirya terminará llamándose Stefano Carboni y teniendo el rostro del actor Raul Bova.

\section{LOS ACTORES DEL DRAMA: ¿DÓNDE ESTÁN LOS BUENOS Y LOS MALOS?}

\section{EL MITO DE LA ITALIANIDAD}

Nassirya nace con una explícita y obvia intención celebrativa que determina la evolución narrativa y las elecciones estilísticas: se trata de la conmemoración de un evento trágico de la historia italiana que debe ser releído y valorado. Sin embargo, la serie realiza un traslado a nivel de valorización: la memoria del hecho en sí se convierte en la celebración de la especificidad de ser italianos. No es, de hecho, el valor militar el que es celebrado, o la acción heroica, sino el estereotipo de los italianos "buena gente", pendientes de las personas y de sus pequeños o grandes problemas, que también en guerra llevan paz y democracia, mantienen las promesas, son dife- 
rentes de todos los otros aliados $-\mathrm{y}$, sobre todo, como veremos, de los norteamericanos, arrogantes, prepotentes y también corruptos.

La especificidad italiana está constituida por dos propiedades fundamentales: el buen sentido y los buenos sentimientos, que se estructuran como dos competencias precisas e interconectadas: una competencia patémica, basada esencialmente en el sentimiento de la empatía que lleva al cuidado del otro, y una competencia pragmática, que se encarga de un hacer que realiza tal cuidado a través de la acción: un hacer a menudo humilde, pero siempre útil y eficaz, justamente en su consciente y realista modestia. En resumen, un mundo de pequeñas buenas acciones más que un actuar estratégico en general organizado a nivel político y militar. Así si, en una subordinada oposición militar vs. civil, la acción de los italianos se coloca claramente en el segundo aspecto, presenta además otra característica importante: consigue tener éxito no porque sea apoyada por una organización fuerte y estructurada, sino por la capacidad del contingente italiano de activar redes locales de amigos, conocidos y personas que se prestan como ayudantes para la realización de la obra. Detrás del actuar de los italianos no está, en resumen, un estado con su estructura, sino redes personales e individuales: la familia sobre todo (sólo gracias a la ayuda de la mujer, médico en Italia, Stefano Carboni conseguirá tener la incubadora para el hospital); después, los amigos y los compañeros (el conmilitón que consigue ajustar el desalinizador). Está aquí valorado uno de los rasgos más estereotípicos de la italianidad: el arte de arreglárselas, la ingeniosidad italiana capaz de superar la ausencia de organización basándose en las amistades o relaciones personales, en la gran fuerza de las familias, más o menos organizadas ${ }^{3}$.

¿En qué se puede basar entonces una identidad nacional si no es en la pertenencia común a un estado, a una organización, a una estructura? Paradójicamente, justo en el coexistir transversal de las diferencias individuales que la común "italianidad" no elimina sino, al contrario, valora: es precisamente la existencia de singularidades lo que transforma en riqueza a la especificidad italiana. Desde las primeras escenas, durante el viaje en avión que transporta al contingente a Irak, la voz en off describe los diferentes perfiles y las diversas motivaciones de cada uno de los militares: hay quien va para pagar el préstamo de la casa de su hija, quien lo hace para aplazar el matrimonio con su novia de toda la vida, quien lo hace para eliminar una mancha en el propio pasado, etc. Lo que reúne a esta diversidad es justo el hecho de estar juntos, unidos para la misma misión. Como dice la voz en off: "Todos tienen algo personal y privado que pedir a esta misión. Lo único que no quieres es irte solo".

Podríamos decir entonces que la italianidad es, sobre todo, un modo de "estar juntos", aunque también de diversas formas: cada uno es italiano a su manera, pero al mismo tiempo somos todos italianos de la misma manera. Individualidades diferentes, como se puede ver también en la lengua: prácticamente cada militar habla una variedad regional del italiano, con acentos muy marcados y evidentes, pero tratándose siempre de la misma lengua.

${ }^{3}$ Debemos esta observación a Isabella Pezzini, a la que damos las gracias. 
Esta caracterización del contingente italiano como humano y humilde (y, justo por esto, constructivo) está valorada fuertemente por la construcción narrativa de la ficción, que no pone tanto en escena una evolución sobre el plano de la acción (podemos decir, más bien paradójicamente ya que el contingente está ahí para hacer) cuanto sobre el plano del ser, con una progresiva adhesión por parte de los diferentes miembros del contingente a los valores (iguales para todos) de la acción que se está llevando a cabo.

Como se ha dicho, cada uno tiene una motivación personal: la solicitud de destino es, pues, interior y funcional a la resolución de una necesidad privada. Los soldados italianos no parten en primer lugar para hacer bien a Irak, ni para hacer bien a la nación. Y cuando el escenario iraquí se manifiesta, cuando todos entienden las dificultades y los riesgos que corren, y finalmente se dan cuenta de que están en guerra, muchos flaquean y algunos amenazan o exigen encarecidamente irse. Sólo gracias a la intervención del héroe Stefano Carboni todos vuelven a encontrar las razones para estar allí y aceptar la propia misión. El texto lo afirma explícitamente: "Llegados a este punto nadie se pregunta qué hemos venido a hacer. Hemos encontrado nuestro lugar".

La ficción, por tanto, no pone en escena a un contingente de héroes que desembarca en Irak. Pone en escena a un contingente de hombres cualquiera, que atraviesan crisis y dudas, que tienen miedo, que sufren por la distancia, etc. La humanidad de estos hombres parte de sus debilidades; su heroísmo parte del hecho de que superan y sacrifican estas debilidades por la causa justa de la civilización.

Lo que la ficción hace ver y pone en el centro de su desarrollo es justamente cómo los soldados italianos superan su fragilidad, cómo encuentran respuestas y razones para estar allí. Y un país como el nuestro, que en cuanto a Irak está dividido entre pacifistas e intervencionistas y que ha tenido muchas dificultades para entender las razones y la sensatez de esa expedición (mucho más porque ha tenido que pagar con vidas humanas), este era el punto, esta era la respuesta que servía. La ficción no presenta una respuesta y un conjunto de valores constituidos y asumidos de primeras, sino un conjunto de razones que se imponen progresivamente y que vencen a las dudas, a los miedos y a los abandonos aunque legítimos (y legitimados por la narración).

Nassirya, de esta manera casi transversal -que representa una debilidad, un abandono, para después rescatarlo a través de un desarrollo narrativo que lo compensa- consigue valorar a los italianos al menos de dos modos: por una parte, valora la humanidad de los soldados italianos, que sufren como todos, tienen miedo como todos, pero permanecen allí porque entienden las nobles razones que dan sentido a sus acciones; por otra parte, valora su adaptabilidad, desde el momento en que los soldados saben entender las situaciones, adaptarse a ellas, adecuarse -en definitiva, saben encontrar su propio camino, una vez entendida la importancia de su empresa. 


\section{EL PAPEL DEL HÉROE}

Dentro de esta organización narrativa tiene su propio lugar el héroe Stefano Carboni (Raul Bova). No solamente porque en el plano narrativo es desde todos los puntos "el héroe" sino porque está presente en niveles muy diferentes al texto, jugando más papeles.

Es, naturalmente, el protagonista por excelencia de la acción que se cuenta en el plano narrativo. Pero es el héroe no sólo porque hace más que todos los demás (ni tampoco porque esté jerárquicamente antepuesto a los otros), sino, sobre todo, porque moldea a los demás, es el que los manipula localmente 4 : sermonea a los suyos haciéndoles encontrar razones para quedarse; manipula al pueblo iraquí para votar; manipula al niño "corrigiendo" la tendencia a delinquir que parece manifestar; manipula a su mujer, induciéndola a mandar a Nassirya la incubadora y haciéndole reaccionar al luto que la aflige, etc. Estamos frente a un héroe eficaz y su eficacia es verbal. Stefano Carboni es un verdadero y claro héroe de las palabras. En una secuencia clave de la ficción, mientras todos acuden con kalashnikov, metralleta y tanques apuntando al pueblo que está decidido a votar en las primeras elecciones democráticas del país, él tira las armas y se limita a hablar -con un gesto casi cristológico que lo convierte en predicador antes que en soldado.

Además de ser protagonista y héroe, Stefano Carboni es también, a menudo, la voz narradora y el observador. Es un narrador homodiegético (porque está presente en la historia narrada), pero el enfoque está alejado de los hechos: cuando mira, no forma parte de la acción. Stefano Carboni, pues, se convierte a menudo en una especie de ojo intradiegético pero fuera de lugar, que observa (un poco a distancia y con una pietas casi religiosa) y entiende. Especialmente significativa, en este sentido, es la escena en la que todos los soldados del contingente llaman a sus familias excepto él, que los observa con comprensión y afecto y elige para nosotros, con su visión, estos momentos de gran intensidad emotiva para los protagonistas de la diégesis, los soldados italianos. Nosotros, espectadores, nos encontramos de frente a él que los mira a ellos. Él se convierte así en la figura del observador, nos encarna a nosotros que observamos, estableciendo con nosotros espectadores un vínculo de identificación.

Por lo demás, la ficción quiere proponerlo desde el principio como la voz y la mirada encargadas de interpretar los hechos, es decir, "el portavoz" para nosotros espectadores de ese acontecimiento, el mediador entre ellos, allí, y nosotros, en casa.

Basta ver el inicio que presenta enseguida a Stefano Carboni como el narrador de la historia: es él el que nos dirá cómo están las cosas, porque es él la única voz y el único rostro que la cámara enfoca para narrarnos lo acontecido. Solamente al final des-

\footnotetext{
4 Cada vez que hablamos de "manipulación" no hacemos referencia necesariamente a una acción persuasiva connotada negativamente, sino a que una acción induce a hacer otra cosa. Dentro de la teoría narrativa de Greimas, el sujeto de la acción, antes de comenzar la propia actuación, debe ser inducido a hacer, basándose en un conjunto de valores (objetivos prácticos y principios abstractos) que lo orientarán en su recorrido. Quien alimenta esos valores - puede ser otro sujeto concreto, como un padre o un superior, o una instancia interna a sí mismos, como en los casos en los que el Super Yo "impone" al Yo las tareas, o una instancia abstracta, como el Destino- y pone al sujeto en las condiciones de hacer (confiriéndole poder, saber, deber y querer), es aquel que manipula al sujeto y lo moldea.
} 
cubrimos que no es en absoluto el único que ha hecho esa grabación, de hecho le ha precedido otro de los suyos. Por lo tanto, no es el único que ha narrado, como portavoz, el acontecimiento, sino sólo uno entre otros. Sin embargo, la ficción, durante dos episodios enteros, nos lo ha presentado como la única voz legítima de la narración.

El héroe, por tanto, no moldea solamente a sus soldados, en el plano narrativo, induciéndolos a estar motivados, sino que nos moldea sobre todo a nosotros, espectadores en casa, en el plano de la enunciación. Eso que llegamos a saber lo aprendemos a través de su relato y en diferentes puntos (a partir de ese inicio, apenas citado) parece mirarnos directamente, más allá de la pantalla, con una mirada a cámara que es la típica mirada de interpelación al espectador.

Se crea así un eficaz sincretismo entre el contingente y nosotros: tanto ellos como nosotros moldeados por su mirada y por sus palabras; tanto ellos como nosotros debemos encontrar las razones para estar (o para irnos) a Nassirya. Y es el protagonista el que nos las da.

\section{LOS PROBLEMÁTICOS AMERICANOS}

La diferencia y la especificidad de los italianos con respecto a todos los demás contingentes se centran sobre todo en la finalidad de la misión: esto es lo que la ficción, desde el principio hasta el final, nos dice. Los italianos no están en Irak para hacer la guerra, sino para llevar la paz, y -algo muy importante- la democracia.

Este traslado del relato sobre el tema de la paz tiene importantes consecuencias narrativas, porque obliga a una reformulación más bien radical de los papeles actanciales y a una consecuente re-atribución de los valores a cada uno de los actores. En concreto es el eje amigo-enemigo (en términos semióticos, ayudante y antisujeto) el que es subvertido. Debido a la insistencia continuada sobre la función de paz y no de guerra de nuestra misión, el papel del antisujeto no puede ser desempeñado por los iraquíes: de lo contrario terminaríamos en guerra con ellos. Se crea así la necesidad de construir otras figuras antagonistas, otros enemigos contra los que luchar.

Entre las diferentes fuerzas y figuras que se oponen a la realización de los proyectos de nuestros soldados, y sobre todo de su valeroso comandante, son sobre todo los estadounidenses los que se conforman progresivamente como antisujetos.

Los norteamericanos encarnan en este contexto varias configuraciones de valores. En el primer encuentro con las tropas italianas, un joven e inconsciente soldado americano da vueltas en skateboard, pero justo después, aterrorizado, está a punto de disparar a un indefenso niño iraquí: lo asesinaría si no interviniera con mano firme nuestro héroe italiano. Desde el principio, se delimita un campo de valores donde los soldados estadounidenses están marcados por una cierta inconsciencia y ligereza, unidas al mismo tiempo a una inútil y absurda crueldad. Por el contrario, el italiano es serio y reflexivo, y su fuerza aparece moderada y sabia, nunca sin motivos y siempre contenida por una empatía instintiva hacia el otro.

Pero es en los niveles más altos donde la oposición se hace más explícita y marcada: el comando estadounidense es insensible a las necesidades de la población, arrogante y relacionado con el poder corrupto. En lugar de impedir el saqueo del 
museo, cubre al traficante americano que especula sobre los restos arqueológicos robados; no distribuye los víveres sino que avala y favorece el mercado negro. Será el comandante Stefano Carboni el que se opondrá a estas injusticias, pero también en estos casos, muy significativamente, no tanto por restaurar una norma general de la legalidad, cuanto por "explotar" a favor de la población estas fechorías, siguiendo una lógica de presión y casi de extorsión. La confabulación del comandante estadounidense con los traficantes de restos será utilizada para obtener la distribución de los víveres, más que para hacer transparente la gestión del comando.

A las razones de la guerra se oponen las de la paz. Una bomba americana cuesta como una depuradora de agua que salvaría a toda la gente de Nassirya de las enfermedades y de la sed, y Stefano Carboni consigue restaurar el filtro con la ayuda de amigos y conocidos: a la arrogancia y a la corrupción de los estadounidenses se opone la honestidad y el sentido de responsabilidad de los nuestros.

Nos parece que este poco velado filón pacífico y antiamericano se puede explicar con una importante razón de orden, por así decir, extratextual. Una fícción como Nassirya se mueve dentro de una tensión de valores fuertemente polarizada. Por un lado, nace de la exigencia de celebrar el sacrificio de la misión italiana-que, recordémoslo, es una misión de militares: los muertos de Nassirya son soldados, no civiles ${ }^{5}$. La función celebrativa se topa, sin embargo, con la escasa popularidad de la misión italiana. La decisión del gobierno italiano de participar en la misión de Irak de parte de los estadounidenses e ingleses ha sido una elección poco popular. Un difundido sentimiento de adversidad continuaba estando presente también en el momento en que ha sido estrenada la miniserie. ¿Cómo conciliar estos valores antagonistas, claramente irreducibles? La solución adoptada por la ficción ha sido la de transformar a las fuerzas italianas en fuerzas de paz y la de convertir a los estadounidenses en una especie de antagonistas, opuestos en el eje de la oposición implícita subyacente paz vs. guerra. La elección ha consentido de esta manera valorar la intervención italiana como una misión de paz, ocultando sustancialmente las afinidades con las demás fuerzas de ocupación aliadas.

Es interesante observar que una solución análoga ha sido adoptada también durante la transmisión en directo de los funerales de los soldados asesinados (Pozzato y Spaziante, 2007), que presentaban el mismo problema de intentar conciliar tensiones de valores opuestos. El cura durante el funeral definió de hecho a los militares como "operadores de paz y caridad hacia los hermanos", confirmando una necesidad transversal de los medios de comunicación de reforzar el tema de la paz y legitimar por esta vía también la muerte cruenta de los militares.

Obviamente, la paz que los italianos puede llevar a Irak será una paz de pequeñas acciones: la caridad de un poco de comida, el filtro del agua, una incubadora, la relación privilegiada con algún iraquí "bueno", etc. Se puede hablar de una singularización y una personificación de la acción de paz, que no es más -ni podría serlo con estas premisas- que una acción colectiva y política, encaminada a transformar las condiciones generales de una situación, pero que se concreta con las acciones

\footnotetext{
5 En realidad, uno de los muertos es un cameraman que estaba haciendo una grabación para un servicio televisivo en el momento del atentado.
} 
individuales de esas "buenas personas" que son los italianos. Reaparece aquí la oposición que ya hemos indicado entre la política de las grandes potencias (corrupta e inhumana) y la no política de los individuos, basada en la empatía, en los buenos sentimientos, en lo concreto.

\section{LOS IRAQUÍES: NO TODOS ENEMIGOS}

En este apartado se establece lo que podríamos llamar la necesidad de "desenemistar" al enemigo. Los iraquíes en cuanto tales no son nunca representados como enemigos, sino según una gama de diferentes "tipos" humanos. Antes de todo están los iraquíes buenos. El prototipo es el intérprete que colabora con los italianos y se convierte en consejero y amigo. Ejemplo de mansedumbre y buena voluntad, pero también de inteligente sensatez, capaz de una comprensión más matizada de la realidad, se contrapone al hermano rígido y esquemático que, sin capacidad para la dialéctica, termina siendo terrorista kamikaze.

Otro tipo de iraquí es el disidente democrático, el cual, perseguido ya por el régimen de Saddam, es aborrecido también por los políticos que quieren mantener el poder impidiendo el desarrollo de la democracia, exactamente igual que los antiguos tiranos. Amigo de los italianos, es protegido por estos y ayudado hasta el éxito electoral.

Está después la gama de esos que podríamos definir como los "malos-buenos", personajes negativos que sufren una transformación de valores que los vuelve, al menos en parte, positivos o en cualquier modo capaces de alguna buena acción. Entra en esta tipología el desagradable jefe de la policía, reciclado por el viejo régimen, que al final tiene un impulso de dignidad moral; o el pérfido jeque corrupto que, sin embargo, advierte a los italianos del peligro que corren. Es importante observar que estas "conversiones" son siempre las consecuencias narrativas de buenas acciones llevadas a cabo por los italianos, que salvan la vida al policía corrupto o al bebé recién nacido del jeque gracias a la incubadora. En otras palabras, también cuando no son los artífices directos del bien, los italianos son en cualquier caso siempre la causa de la transformación positiva de valores y pragmáticas, cambiando el signo de malo y hostil a bueno y amigo.

La única figura de alteridad irreductible, que escapa siempre a cualquier influencia salvífica, aunque sea la de los italianos, es el terrorista, siempre atroz, malo sin esperanza. Incomprensible por sus motivaciones, no se muestra guiado por racionalidad alguna en sus acciones, siempre locas y extremistas, y parece actuar sólo por un odio sin motivos. Fuera de cualquier lógica racional o humana, es realmente de una maldad irremediable: tortura a los niños, manipula, corrompe o engaña, difundiendo el mal. Si tal polarización no es sorprendente -y ni siquiera es en sí muy interesante-, digna de nota es el tipo de representación. Los terroristas son de hecho siempre representados en el interior de un marco simulado-arabizado, en tiendas improbables (en el desierto o en el centro de Bagdad) decoradas con preciosas alfombras, con música árabe de fondo, según una visión iconográfica más adaptada a un Club Méditerranée que a un grupo terrorista. Nos parece, esta, un versión peculiar de ese orientalismo del que habla Said (1978), que toma aquí la forma de una 
arabización fuertemente estereotipada, de la que no está excluida una alusión a la homosexualidad, como se puede ver en la escena del baño ritual del kamikaze que se prepara para el "martirio".

\section{LAS FORMAS DE MANIPULACIÓN}

A la luz de todo lo que se ha dicho aquí, es casi pleonástico afirmar que la ficción es y quiere ser programáticamente manipuladora. Podemos verlo casi como un verdadero y justo "monumento a los caídos", mediático y no ya marmóreo (los tiempos han cambiado...). No se trata tanto, en el caso de esta ficción, de recuperar la memoria perdida (como podría ser el caso de una película sobre Napoleón o sobre la expedición de los Mille) pero sí de constituirla: de construir una versión compartida y "definitiva" de lo ocurrido en Nassirya y un relato que pueda ser el ejemplo por antonomasia de heroísmo. El camino elegido por la ficción para constituir esta memoria tiene, por otra parte, los rasgos de una modalidad historiográfica especialmente querida para la cultura italiana: las memorias. En la ficción, de hecho, las cartas tienen un papel esencial: es este el modo que tiene el héroe de contar su historia. La mujer en el momento de la despedida le pide a Stefano cartas y no llamadas y él, todas las noches, escribe, relatándonos a nosotros espectadores lo que sus ojos ven y eligen para la consorte.

De esta suma de memorias se derivan diferentes consecuencias: por una parte encontramos una historia íntima, no la historia oficial y distante de los políticos, de los jefes, de las instituciones; por otra, tenemos un texto que asume enseguida la marca de autenticidad (las memorias son testimonios verdaderos por excelencia); por último, el espectador es puesto frente al momento en el que el documento histórico se hace, en el momento en que la historia se escribe (y la ficción, como hemos dicho hace poco, debe justamente construir una memoria).

A través de esta modalidad de "escritura de la historia en directo", la ficción propone a la vez la construcción de:

- un discurso de legitimación de la acción como acción de paz, no de guerra;

- un discurso nacional de refuerzo de la identidad italiana;

- un discurso de monumentalización basado en el valor del heroísmo.

Ya hemos tratado del discurso de legitimación de la acción como acción de paz. El hecho de que la finalidad de la acción militar sea llevar civilización y democracia es repetido de manera programática, ya sea en los momentos en que se debe hacer ver a los iraquíes el objetivo de su presencia (es decir, en el diálogo con el Diferente), ya sea en el enfrentamiento con los otros contingentes militares presentes allí (es decir, en el diálogo con el Otro aparentemente parecido a nosotros).

El hecho, sin embargo, de que se realice para llevar civilización y democracia no significa obrar en paz. A nadie convencería un argumento semejante: ni, a nivel intradiegético, a los soldados de la ficción, puestos diariamente a prueba permaneciendo allí; ni, a nivel extradiegético, a los italianos-espectadores que han afrontado un gran debate con respecto a esta cuestión. La ficción parece decirnos que se trata efectivamente de combatir una guerra, pero una guerra sui generis, contra la natura- 
leza y contra la falta de civilización: de ahí que la individualización del antisujeto -en la naturaleza impracticable, en la pobreza y, por último, en la inhumanidad de quien la explota- sea explícita. Especialmente significativo, en este sentido, es un pasaje en el que el comandante Stefano Carboni explica a sus compañeros la verdadera naturaleza de la guerra que tienen delante: "hace un tiempo tiraban bombas. [...] Ahora, sin embargo, nuestro enemigo es el desierto, el calor, el sol, la sed...".

En este cuadro, las armas tienen un papel especial: estas naturalmente son centrales, tratándose de una situación de paz pero de guerra, son usadas sólo con fines defensivos (y la ficción insiste mucho en el hecho de que los italianos nunca deben disparar los primeros).

Para hacer más "comprensible" la idea de una acción de paz que se manifiesta a través de una acción de guerra y con las armas, la ficción recuerda un precedente citando dos veces (y ambas en puntos en los que la referencia resulta realmente un "postizo", forzado) la intervención italiana en Kosovo, que sí había dado pie a debates, pero al fin y al cabo había sido aceptada por los italianos de manera menos polémica, con un mayor apoyo.

El segundo discurso que la ficción sostiene, a nivel ideológico-manipulador, es el nacionalista de refuerzo de la identidad italiana. La misión para la democracia puesta en escena es una especificidad italiana. Mientras los otros países han elegido otras posiciones (los norteamericanos explotan económicamente la situación, los ingleses se esconden, etc.), los italianos tienen un objetivo preciso, específicamente suyo, que los diferencia de los otros: deben llevar la democracia. Interesante, para esto, el papel de la bandera. Esta aparece en la ficción en tres momentos diferentes con funciones diversas:

- al principio, para identificar al contingente;

- en el punto más estratégico de la ficción (no por casualidad justo a la mitad), para calificar al contingente: nada más terminar los procedimientos de votación de las primeras elecciones democráticas del país, aparece la bandera -casi para decir: eso que ha ocurrido es mérito de Italia, la bandera es nuestra firma;

- al final, durante los funerales, para acoger al contingente, para expresar la procedencia de los muertos, ahora héroes.

La bandera, en resumen, acompaña el recorrido narrativo de nuestros héroes a lo largo de toda su experiencia en Nassirya: de la prueba significativa (prepararse para partir, re-estructurar el cuartel, conocer el territorio, etc.) a la principal (crear la democracia) y a la acción glorificadora (la muerte) ${ }^{6}$. El discurso nacionalista de la ficción, sin embargo, no termina aquí; este es más complejo e indirecto, no tematiza nunca, de manera explícita y "vulgar", un "viva Italia", pero valora el tema de la unión civil. La ficción nos dice, desde el principio y muchas veces: lo importante es permanecer unidos, lo importante es estar juntos, hacer comunidad. Stefano

\footnotetext{
${ }^{6}$ Hacemos aquí referencia a la teoría narrativa de Greimas (1970; 1983), según la cual -en la línea de la teoría de Vladimir Propp-en un cuento el héroe está siempre sometido a tres pruebas: la calificadora, en la que se le otorga lo necesario para cumplir la siguiente actuación; la principal, que constituye la verdadera y propia acción, y la glorificadora, con la ejecución de una tarea especialmente difícil que lo reafirma en su papel de héroe.
} 
Carboni lo dice al principio; lo repite después, cuando los otros no ceden a la tentación de volver a casa para no dejarlo solo; y lo recuerda al final, cuando la tarde anterior a la explosión, se congratula con todos los miembros del contingente porque han permanecido unidos. La ficción, por tanto, no habla nunca de heroísmo individual: habla de esa importancia de sentirse juntos, que los hace héroes.

Pensemos, a este respecto, en lo que se ha escrito sobre el vínculo entre el monumento a los caídos, el nacionalismo y la capacidad para crear unas comunidades imaginadas (Anderson, 1983). Nassirya juega exactamente con este vínculo: a través de un monumento mediático in memoriam (que, casi con una mise in abyme, tematiza el tema de permanecer juntos), consolida el vínculo de una comunidad y refuerza el sentimiento nacionalista. El valor que construye heró́smo y nacionalismo es estar juntos entre italianos.

$\mathrm{Al}$ final, la ficción elabora un discurso claro de monumentalización basado en el valor del heró́smo. Las razones por las que, partiendo de esta, podemos hablar de heroísmo son tantas: por el propio sacrificio de estos chicos que eligen estar en un lugar peligroso (antes e independientemente de la muerte que seguirá); por las actuaciones manifestadas (los tiroteos, las elecciones, el robo de las pastillas, donde los soldados se comportan como héroes); por la muerte que sobreviene. Se trata en cualquier caso de un heroísmo a la italiana, es decir, de un heroísmo de corazón, que comete errores pero que después sabe solucionarlos, que no espera la muerte sino que consume la vida: parece que sólo se es héroe si se muere, se dice polémicamente al final, subrayando que no es ese el heroísmo que interesa a nuestro contingente (aunque después todos mueran).

Con respecto a este discurso, la reanudación de la verdadera ceremonia final, con la que Nassirya se termina, constituye una especie de sanción glorificadora del heroísmo en sí mismo. En las escenas documentales o en el "desfile" final de las verdaderas identidades de los soldados del contingente italiano, realidad y ficción se mezclan, hasta incluso confundirse. La ficción sugiere, de hecho, un repentino (no preparado) pasaje desde el plano ficcional al punto en el que los soldados están muertos y, por tanto, están glorificados. Se sale de la ficción y se entra en la historia con el funeral real, haciendo del heroísmo (del momento glorificador, para decirlo en términos semióticos) el puente entre irrealidad y realidad.

Pero no sólo hay esto;, no se trata sólo de un anclaje de la ficción en la realidad. Está también (como se ha mencionado antes) un movimiento inverso, que de la realidad manda a la ficción. Las identidades reales de las víctimas de Nassirya, de hecho, desfilan según una convención estilística típicamente cinematográfica, casi como si fueran los actores de la película que acaba de terminar.

Se produce, en resumen, en los pocos minutos finales de la serie, una especie de suspensión de la heterogeneidad entre el mundo real y el mundo de la ficción. La gloria evidentemente consiente a los hombres verdaderos volverse héroes de una ficción (las identidades en orden de aparición) y a los héroes de una ficción "pasar" por héroes verdaderos (por lo que el "esperado" funeral de los muertos de la ficción es sustituido por el funeral de los muertos reales).

Hay una dimensión -la de la memoria y la celebración del heroísmo- en la que la realidad y la ficción se superponen y se intercambian el lugar. Sin traicionar, por esto, ni la historia ni los sentimientos. 


\title{
BIBLIOGRAFÍA
}

Anderson, B., 1983, Imagined Communities. Reflections on the Origin and Spread of Nationalism. Londres, Verso.

Assmann, A., 2002, Ricordare. Forme e mutamenti della memoria culturale. Bolonia, Il Mulino.

Buonanno, M., 2003 (a cura di), Storie e memorie. La fiction italiana, l'Italia nella fiction. Roma, Rai Eri.

Greimas, A. J., 1970, Du sens. Essais semiotiques. Paris, Seuil.

—, 1983, Du sens II. Essais semiotiques. Paris, Seuil.

Pozzato, M. P. y SPAziante, L., 2007, "I caduti di Nassiriya: un rituale mediatico di lutto nazionale", en Cosenza, G., (a cura di) Semiotica della comunicazione politica. Roma, Carocci.

SAID, E. W., 1978, Orientalism. Londres, Routledge.

\section{RESUMEN}

Las autoras realizan un análisis de Nassirya, miniserie televisiva que ficcionaliza y conmemora un evento trágico de la historia: la muerte de un contingente de soldados italianos en la guerra de Irak. La memoria del hecho se convierte en recreación y celebración de la identidad italiana, la italianidad, a través de un relato del heroísmo de unos hombres cualesquiera. La ficción transforma a los italianos en fuerzas de paz y opone su sensible humanidad a la corrupción e inhumanidad de los norteamericanos, antagonistas que toman el lugar de un enemigo iraquí, imposible en un relato de paz. El espectador es puesto ante el momento en que la historia se escribe. Y en la construcción de la memoria, realidad y ficción se superponen e intercambian sus lugares.

Palabras clave: ficción, relato, historia, identidad italiana, memoria.

\section{Nassirya: an Italian series between fiction and historical reality}

\begin{abstract}
The authors conduct an analysis of Nassirya, television miniseries that fictionalizes and commemorates a tragic event in history: the death of a contingent of Italian soldiers in the Iraq war. The memory of the fact becomes recreation and celebration of Italian identity, the Italianity, through a story of heroism of men whatever. Fiction transforms Italian soldiers into peacekeepers and opposes their sensitive humanity to the corruption and inhumanity of US-Americans, antagonists that take the place of an Iraqi enemy, impossible in a story of peace. The viewer is set to the time in which history is written. And in the construction of memory, reality and fiction overlap and change places.
\end{abstract}

Keywords: Fiction, Narrative, History; Italian identity, Memory. 